\title{
Feasibility and First Results of Heart Failure Monitoring Using the Wearable Cardioverter-Defibrillator in Newly Diagnosed Heart Failure with Reduced Ejection Fraction
}

\author{
Henrike Aenne Katrin Hillmann ${ }^{\dagger}$, Stephan Hohmann ${ }^{+}{ }^{\mathbb{C}}$, Johanna Mueller-Leisse, Christos Zormpas, \\ Jörg Eiringhaus, Johann Bauersachs $\mathbb{(})$, Christian Veltmann (1) and David Duncker *(-)
}

check for updates

Citation: Hillmann, H.A.K.; Hohmann, S.; Mueller-Leisse, J.; Zormpas, C.; Eiringhaus, J.; Bauersachs, J.; Veltmann, C.; Duncker, D. Feasibility and First Results of Heart Failure Monitoring Using the Wearable Cardioverter-Defibrillator in Newly Diagnosed Heart Failure with Reduced Ejection Fraction. Sensors 2021, 21, 7798. https:// doi.org/10.3390/s21237798

Academic Editor: Mario

Munoz-Organero

Received: 31 October 2021

Accepted: 21 November 2021

Published: 23 November 2021

Publisher's Note: MDPI stays neutral with regard to jurisdictional claims in published maps and institutional affiliations.

Copyright: (C) 2021 by the authors Licensee MDPI, Basel, Switzerland. This article is an open access article distributed under the terms and conditions of the Creative Commons Attribution (CC BY) license (https:/ / creativecommons.org/licenses/by/ $4.0 /)$.
Hannover Heart Rhythm Center, Department of Cardiology and Angiology, Hannover Medical School, 30625 Hannover, Germany; hillmann.henrike@mh-hannover.de (H.A.K.H.); hohmann.stephan@mh-hannover.de (S.H.); mueller-leisse.johanna@mh-hannover.de (J.M.-L.); zormpas.christos@mh-hannover.de (C.Z.); eiringhaus.joerg@mh-hannover.de (J.E.); bauersachs.johann@mh-hannover.de (J.B.); veltmann.christian@mh-hannover.de (C.V.)

* Correspondence: duncker.david@mh-hannover.de; Tel.: +49-511-532-82604

t These authors contributed equally to this work.
Keywords: wearable cardioverter-defibrillator; sudden cardiac death; heart failure; heart failure monitoring

\section{Introduction}

Patients with heart failure with reduced ejection fraction (HFrEF) secondary to ischemic or non-ischemic cardiomyopathy may be at high risk for malignant arrhythmias and sudden cardiac death [1-3] without meeting implantable cardioverter-defibrillator (ICD) implantation criteria [4]. The wearable cardioverter-defibrillator (WCD) can be used in such patients during HFrEF therapy optimization and ongoing risk stratification [2-6]. Previous studies have analyzed the effectiveness of the WCD regarding different indications in patients with ischemic and non-ischemic cardiomyopathy [1,3,7-14]. While the primary purpose of the WCD is the prevention of sudden arrhythmic cardiac death, it also provides near-continuous telemetric monitoring of parameters of interest in heart failure $[15,16]$. These parameters, such as heart rate or step count, are accessible via a secure web platform (ZOLL Patient Management Network, ZOLL, Pittsburgh, PA, USA).

In clinical practice, patients with newly diagnosed HFrEF are typically discharged on starting doses of guideline-directed medical therapy and are scheduled for a follow-up 
visit after three months. However, in a significant fraction of patients, medication is not up-titrated to adequate target doses after the first three months [17]. An early identification of patients without sufficient left ventricular ejection fraction (LVEF) improvement would provide the opportunity for intensified follow-up and re-evaluation in this subgroup.

The aim of this study was to evaluate the clinical relevance of the additional telemetric parameters recorded and provided by the WCD and to identify potential early predictors of LVEF improvement at 3-month follow-up.

\section{Methods}

The PROLONG-II study enrolled patients who received a WCD (LifeVest, ZOLL, Pittsburgh, PA, USA) at Hannover Medical School [18]. The aim of the present study was to provide extended follow-up after WCD prescription. A subgroup of patients included in the PROLONG-II study with newly diagnosed heart failure who received a WCD at Hannover Medical School between April 2013 and December 2017 was included in this retrospective single-center analysis. Additional inclusion criteria were an average WCD wear time of at least $20 \mathrm{~h}$ per day and the availability of data for at least one additional heart failure parameter of interest (heart rate, step count, or body position). Exclusion criteria were chronic heart failure, e.g. patients after explant of an ICD, an average WCD wear time lower than twenty hours per day, and no available heart failure parameters for heart rate, step count, or body position.

Baseline characteristics were taken at the date of WCD prescription, at the 3-month follow-up, and date of the latest follow-up, as available. Characteristics included medical history, clinical status, LVEF, and 12-lead ECG. LVEF was routinely assessed by echocardiography using Simpson's method. All measurements were made in the same center by trained physicians, according to current recommendations for echocardiographic measurements $[19,20]$.

All patients gave informed consent. The present study was conducted in compliance with the Declaration of Helsinki and was approved by the Ethics Committee of Hannover Medical School, Germany.

\subsection{WCD Data}

WCD data were collected via remote monitoring, using an internet platform provided by the manufacturer (ZOLL Patient Management Network, ZOLL, Pittsburgh, PA, USA) (Figure 1).

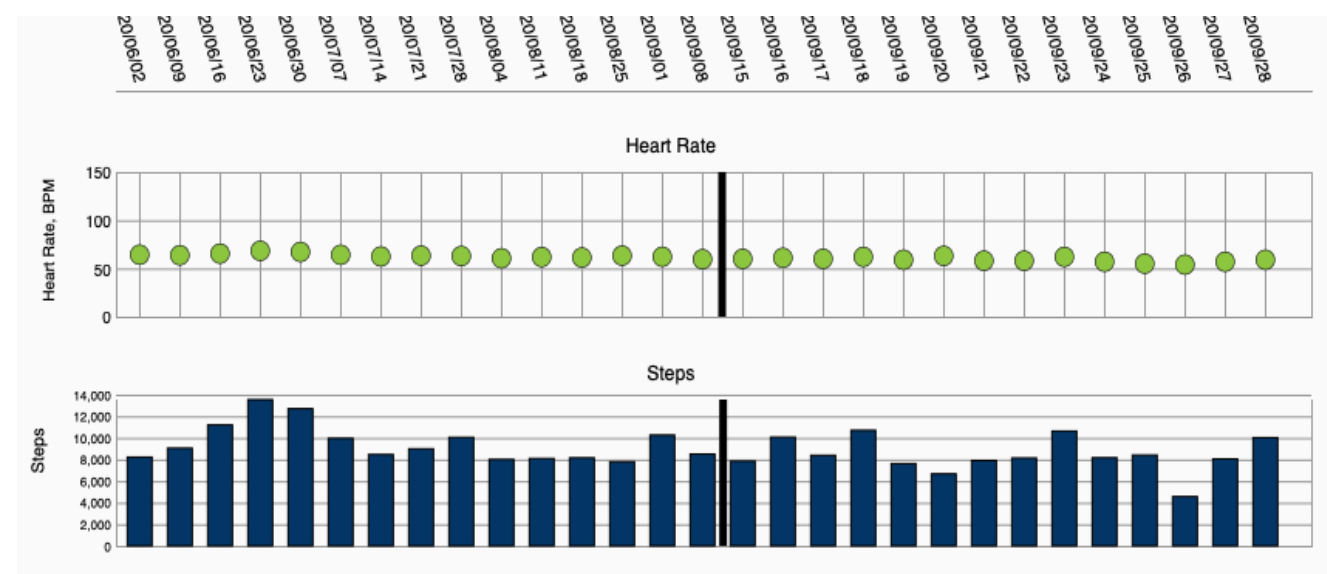

Figure 1. Heart failure parameters heart rate and step count, displayed via remote monitoring.

Heart failure parameters included in the analysis were heart rate and step count, recorded in five-minute intervals. Data were monitored during the period of heart failure therapy optimization. Five-minute heart rate variability approximate (HRV5), a surrogate for beat-to-beat heart rate variability, was calculated as the cycle length standard deviation over all data points per 24-h period. HRV5 is closely related to the standard deviation 
of the average normal-normal intervals (SDANN), an established measurement of heart rate variability [21].

When comparing the first and last seven days of usage, only patients with at least 14 days of wear time were included to avoid data overlap. Using the term "wear time", following the specific criteria chosen by the WCD manufacturer, the first and last day of wear, as well as days with usage below fifteen minutes per day, were excluded.

Regarding LVEF response, patients with an absolute improvement of at least 10 percentage points between prescription and 3-month follow-up were classified as LVEF improvers.

\subsection{Statistics}

Data extraction and merging were performed using R (Version 4.0.1, The R Foundation for Statistical Computing, Vienna, Austria) and Python (NumPy, version 1.19.5, and Pandas, version 1.2.4, Python Software Foundation, version 3.8.6). Heart rate was calculated as the mean of a day, and step count was given as the sum of the day before further analysis. For heart rate and HRV5, data provided as value "zero" from the WCD were excluded from further analyses. Categorical variables are presented as numbers and percentages. Continuous data are presented as median and interquartile rate (IQR) or mean and standard deviation (SD) where appropriate. Heart rate (bpm) was converted to cycle length (ms) for further analysis. The Wilcoxon test was used for between-group comparisons. For correlation analysis, Spearman's correlation coefficient was calculated. In order to illustrate the diagnostic ability of parameters, receiver operating characteristic analysis was performed.

Three-day rolling averages of WCD-derived parameters were compared between baseline (day 3) and day 45 . Optimum cut-off values for the change in HRV5, daily step count, and daily mean heart rate were identified through receiver operating curves (ROC) and YOUDEN's J statistic. These parameters, along with other candidate predictors for LVEF improvement, were used as predictors in univariate logistic regression models. Significant predictors from the univariates models were then used as covariates in a multivariate logistic regression model. Statistical data analysis was performed using SPSS (Version 26, IBM, Armonk, NY USA), R, and the pROC package for R [22]. $p$-values $<0.05$ were considered statistically significant.

\section{Results}

\subsection{Patient Characteristics}

Two hundred and seventy-six patients between April 2013 and December 2017 met the inclusion criteria for further heart failure parameter evaluation and were included in this analysis.

Eighty-eight (31.9\%) of the patients were female. Mean age was $57.4 \pm 15.3$ years. Etiology was non-ischemic in 174 patients $(63.0 \%)$ and ischemic in 102 patients (37.0\%). Non-ischemic etiology majorly included patients with dilated cardiomyopathy $(n=127)$, myocarditis $(n=22)$, peripartum cardiomyopathy $(n=21)$, or other origin $(n=4)$. Fifty-eight point seven percent $(n=162)$ of examined patients suffered from arterial hypertension, $22.5 \%(n=62)$ from diabetes mellitus, 33.0\% $(n=91)$ from dyslipidemia, and $21.7 \%(n=60)$ from renal failure. Forty-three patients $(15.6 \%)$ had a family history of cardiovascular disease. Mean NYHA functional class at prescription was $2.6 \pm 0.8$. Mean LVEF at prescription was $25.3 \pm 8.5 \%$.

At 3-month follow-up, the mean percentage of the target dose for heart failure medication regarding beta-blocker, Renin-angiotensin system inhibitors, and mineralocorticoid receptor antagonists was higher than at prescription for all named medications. Mean NYHA functional class at the 3-month follow-up was 2.0 \pm 0.6 , mean LVEF at the 3-month follow-up was $34.1 \pm 10.3 \%$. LVEF improvers had a mean delta of $17.7 \pm 6.7 \%$ between prescription and 3-month follow-up, while LVEF non-improvers had a mean delta of $1.9 \pm 4.8 \%$. Patient characteristics at WCD prescription and 3-month follow-up are presented in Table 1. 
Table 1. Patient characteristics at WCD prescription and 3-month follow-up; $S D=$ standard deviation; $\mathrm{LVEF}=$ left ventricular ejection fraction; $\mathrm{WCD}=$ wearable cardioverter-defibrillator.

\begin{tabular}{ccc}
\hline Patient Characteristics & $\begin{array}{c}\text { Baseline } \\
(\boldsymbol{n}=\mathbf{2 7 6 )}\end{array}$ & $\begin{array}{c}\text { 3-Month Follow-Up } \\
(\boldsymbol{n}=\mathbf{2 7 1})\end{array}$ \\
\hline NYHA functional class (mean \pm SD) & $2.6 \pm 0.8$ & $2.0 \pm 0.6$ \\
LVEF $(\%$; mean \pm SD) & $25.3 \pm 8.5$ & $34.1 \pm 10.3$ \\
Beta-blocker $(n, \%)$ & $260(94.2)$ & $255(94.1)$ \\
$\%$ target dose (mean \pm SD) & $51.6 \pm 28.0$ & $62.5 \pm 29.7$ \\
\% target dose (mean \pm SD) & $264(95.7)$ & $265(97.8)$ \\
Renin-angiotensin system inhibitor $(n, \%)$ & $47.9 \pm 28.4$ & $61.8 \pm 31.7$ \\
Mineralocorticoid receptor antagonist $(n, \%)$ & $233(84.4)$ & $235(86.7)$ \\
\% target dose (mean \pm SD) & $46.1 \pm 23.4$ & $54.2 \pm 28.9$ \\
Diuretics $(n, \%)$ & $217(78.6)$ & $213(78.6)$ \\
Digitalis $(n, \%)$ & $25(9.1)$ & $20(7.4)$ \\
Ivabradine $(n, \%)$ & $57(20.7)$ & $48(17.7)$ \\
\hline
\end{tabular}

\subsection{WCD-Use}

Mean wear time of the WCD was $111.8 \pm 74.5$ days and $23.1 \pm 0.9 \mathrm{~h}$ per day. Two hundred and sixty-six patients $(96.4 \%)$ had a wear time of at least 14 days. One hundred and thirty-two patients wore the WCD for at least 90 days (Figure 2).

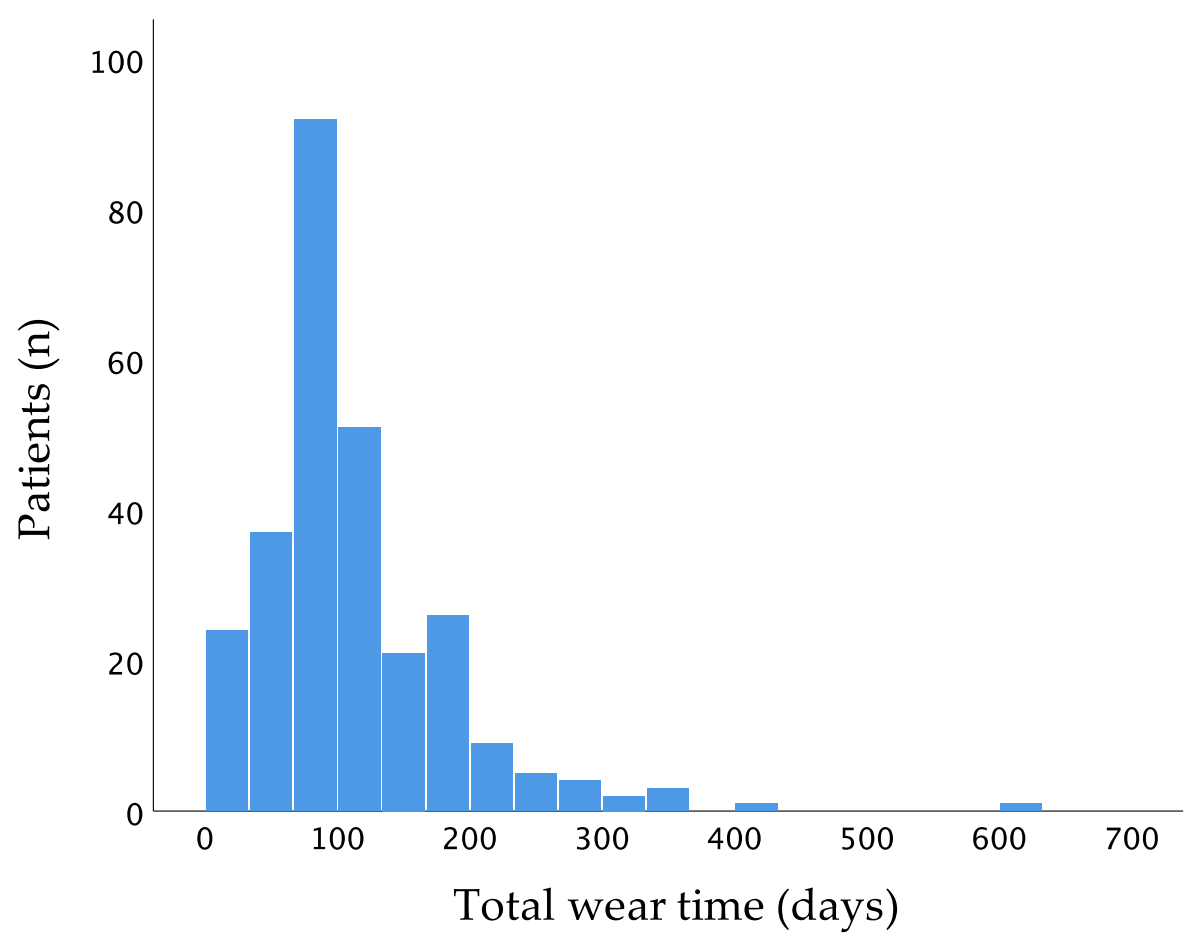

Figure 2. Distribution of wear time of the wearable cardioverter-defibrillator.

Sixty-nine patients (25.0\%) had a prolonged WCD prescription time after 3-month follow-up. Eleven patients (4.0\%) received WCD shocks during the prescription period; all were appropriate shocks for ventricular tachyarrhythmias. There was a total number of 12 delivered WCD shocks. No inappropriate shocks were delivered by the WCD during follow-up. The heart failure etiology was non-ischemic cardiomyopathy in six patients $(54.5 \%)$ and ischemic cardiomyopathy in five patients $(45.5 \%)$. Two patients $(0.1 \%)$ died during the prescription period. One hundred and thirty-three patients $(49.6 \% ; n=268)$ met ICD indication criteria after WCD-prescription time.

Mean change in LVEF between baseline and 3-month follow-up was $9.0 \pm 9.7$ percentage points, with an LVEF improvement of $\geq 10$ percentage points in 118 patients. 


\subsection{Heart Failure Parameters at Baseline and after Three Months}

Median heart rate decreased during WCD-wear time, while median step count and median HRV5 increased over time. Regarding the first 120 days of wear-time, the highest delta was within the first 20 days for each parameter (Figure 3).

A

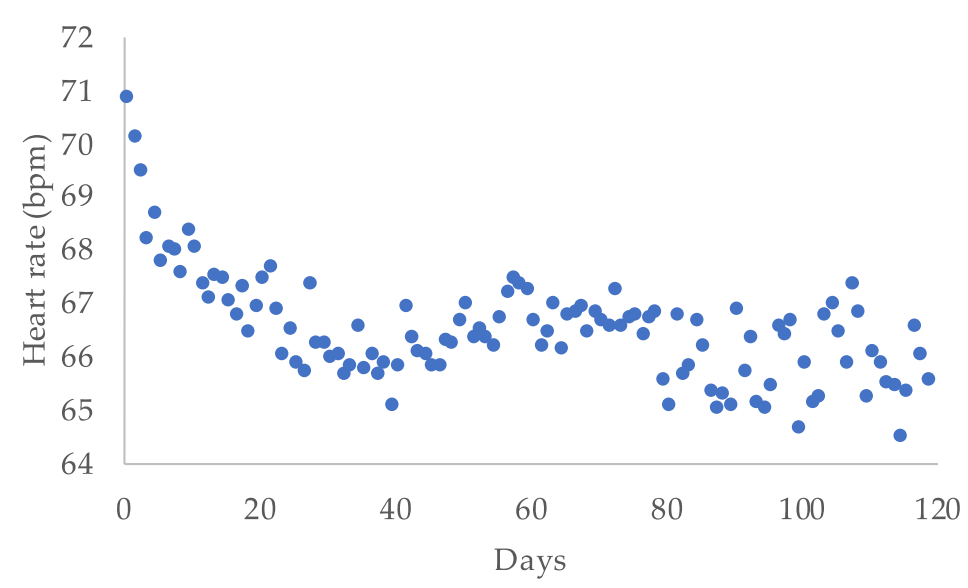

B

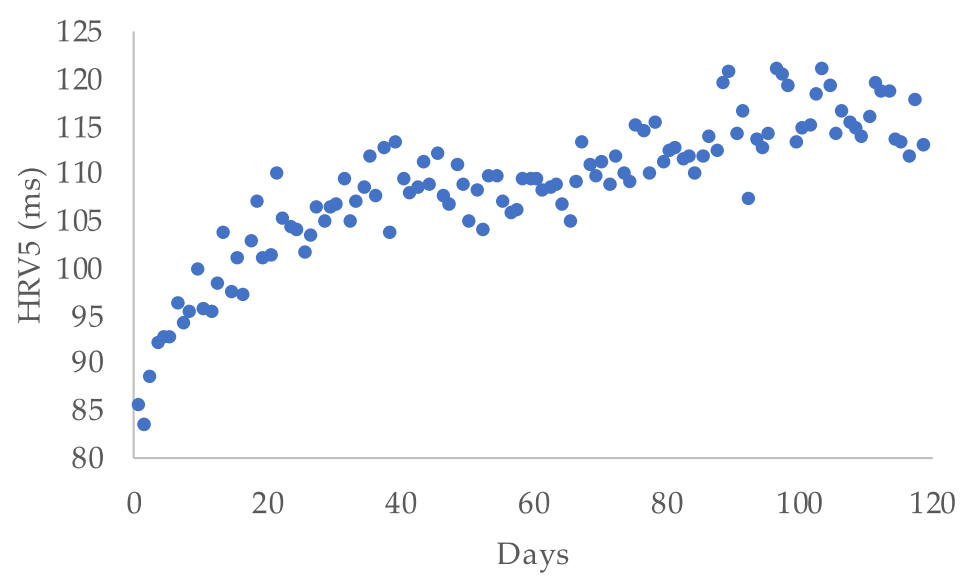

C

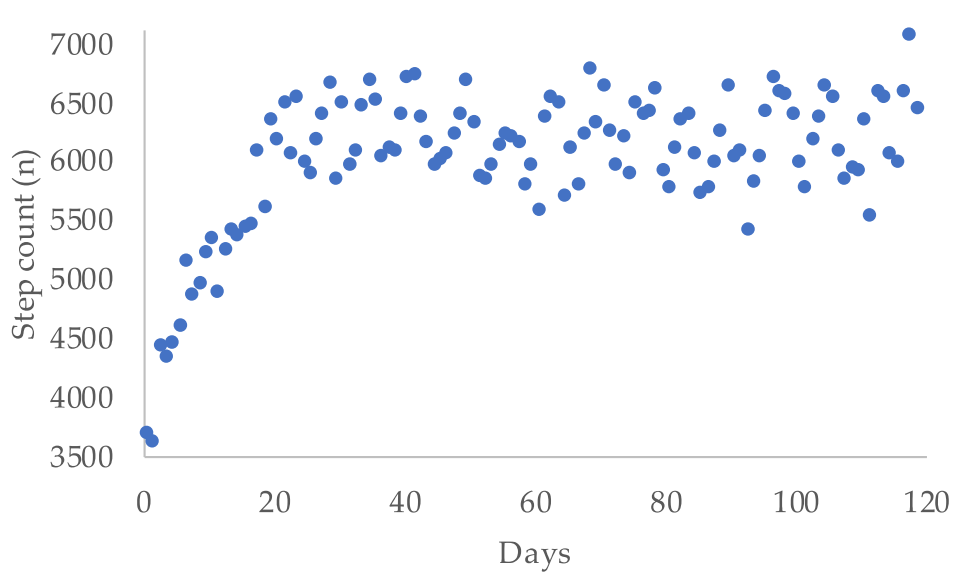

Figure 3. Heart rate (A), heart rate variability approximate (HRV5) (B), and step count (C) displayed as median per day for the first 120 days of wear time for all patients; bpm = beats per minute. 
Between the first and last seven days of usage, median heart rate significantly decreased $(p<0.001)$, while median step count per day $(p<0.001)$ and HRV5 significantly increased $(p<0.001)$ (Table 2, Figure 4).

A

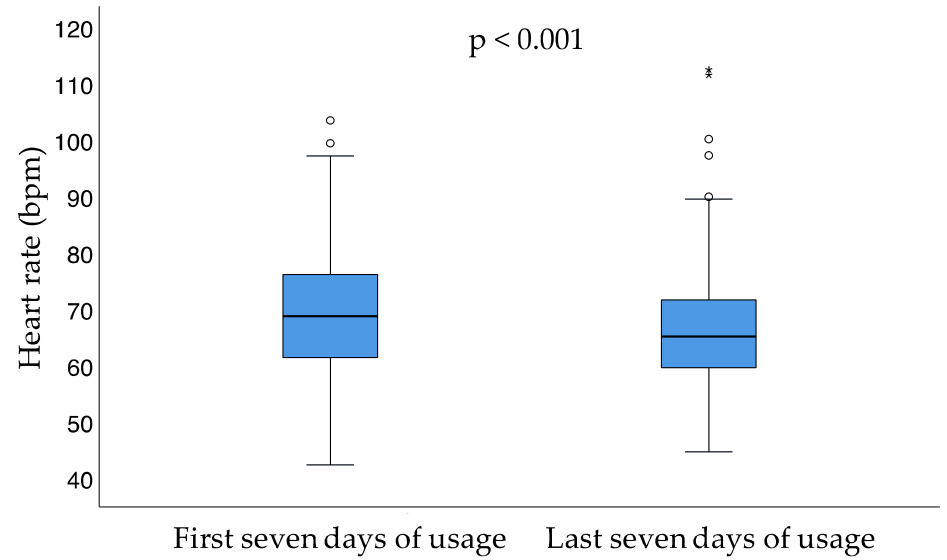

B

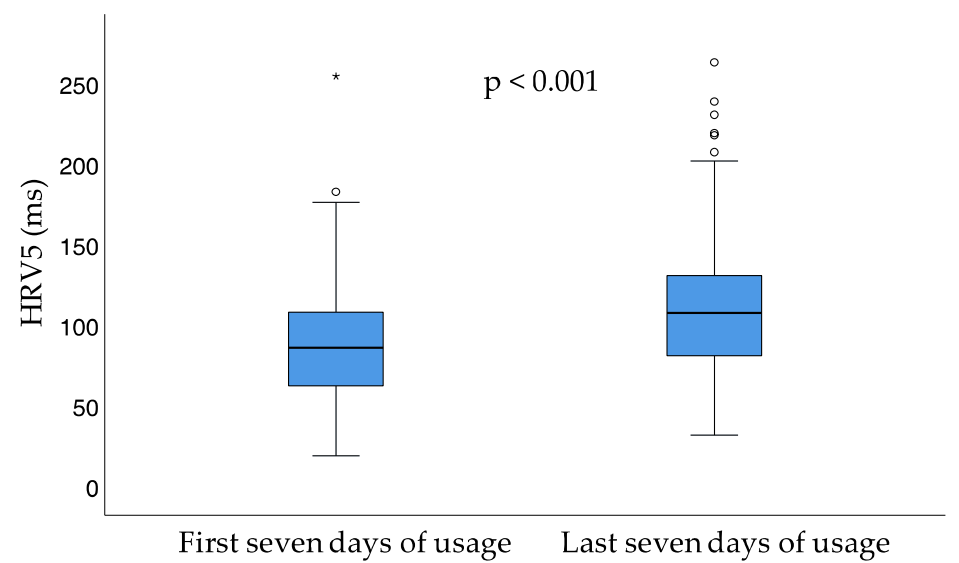

C

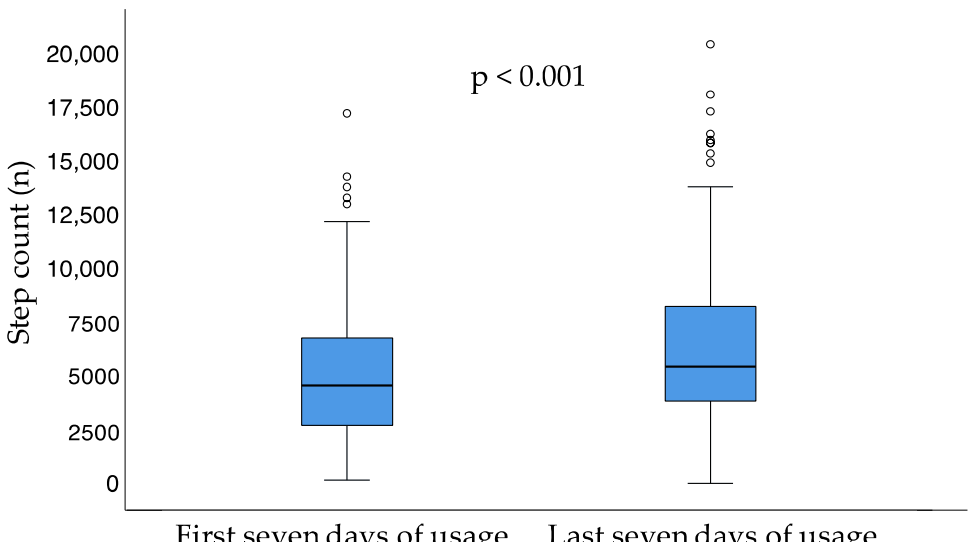

First seven days of usage Last seven days of usage

Figure 4. Heart rate (A), heart rate variability approximate (B), and step count (C) for the first and last seven days of usage; small circles represent outliers (data points outside the range of 3rd quartile $+1.5^{*}$ interquartile range or 1st quartile $-1.5^{*}$ interquartile range); asterisk represent extreme outliers (data points outside the range of 3 rd quartile $+3^{*}$ interquartile range or 1st quartile $-3^{*}$ interquartile range); $\mathrm{bpm}=$ beats per minute; HRV5 = heart rate variability approximate. 
Table 2. Median heart rate, step count per day, and HRV5 between the first and last seven days of usage.

\begin{tabular}{cccc}
\hline Parameter & First Seven Days of Usage & Last Seven Days of Usage & $p$-Value \\
\hline Heart rate (bpm; median; (IQR)) & $69.5(62.0-76.8)$ & $65.9(60.4-72.2)$ & $<0.001$ \\
Step count per day $(n ;$ median; (IQR)) & $4657(2778-6918)$ & $5562(3890-8446)$ & $<0.001$ \\
HRV5 (ms; median; (IQR)) & $89.0(64.8-110.7)$ & $111.0(83.7-134.7)$ & $<0.001$ \\
\hline
\end{tabular}

The results were independent of whether patients did or did not meet the criteria of ICD indication after the prescription time (Figure 5).

Comparing the first and last seven days of usage, the median difference for the heart failure parameter heart rate was 2.8 (IQR -1.7-7.8) bpm. The median difference for HRV5 was $15.6(-5.4-42.0) \mathrm{ms}$. The median difference for step count between the first and last seven days of usage was 712.6 (IQR -676.7-2763.6) steps per day. Executed analyses showed a significance in correlation analysis for several parameters, all associated with correlation coefficients $<0.5$ points (Table 3 ).

Table 3. Correlation analysis: Changes in heart failure parameters between the first and last seven days of usage, and, for left ventricular ejection fraction, between prescription and end of WCD wear time, respectively; $\mathrm{WCD}=$ wearable cardioverter-defibrillator; $\mathrm{LVEF}=$ left ventricular ejection fraction; HRV5 = heart rate variability approximate.

\begin{tabular}{ccc}
\hline $\begin{array}{c}\text { Correlation Analysis for } \\
\text { Heart Failure Parameters }\end{array}$ & Correlation Coefficient (r) & $p$-Value \\
\hline$\Delta$ Heart rate/ $\Delta$ HRV5 & 0.382 & $<0.001$ \\
$\Delta$ Heart rate/ $\Delta$ Step count per day & 0.068 & 0.297 \\
$\Delta$ Step count per day $/ \Delta$ HRV5 & 0.320 & $<0.001$ \\
Age $/ \Delta$ Step count per day & -0.256 & $<0.001$ \\
Age/ $/$ HRV5 & -0.143 & 0.029 \\
Age/ $\Delta$ Heart rate & 0.048 & 0.465 \\
Age/ $\Delta$ LVEF & -0.251 & $<0.001$ \\
$\Delta$ LVEF/ $\Delta$ HRV5 & 0.255 & $<0.001$ \\
$\Delta$ LVEF $\Delta$ Step count per day & 0.189 & 0.005 \\
$\Delta$ LVEF/ $\Delta$ Heart rate & 0.028 & 0.684 \\
\hline
\end{tabular}

\subsection{Early Predictors of LVEF Improvement}

As shown in Figure 3, there was a steep change in heart rate, HRV5, and step count within the first couple of weeks in most patients. We hypothesized that the change in these parameters between baseline and day 45 (the difference in daily average heart rate expressed as cycle length, $\triangle \mathrm{CL}$; the difference in HRV5, $\triangle \mathrm{HRV} 5$; and the difference in daily step count, $\Delta$ steps) could predict LVEF response after three months. Using receiver operating curves with $\Delta C L, \Delta H R V 5$, and $\Delta$ steps, we identified the best cut-off values for the prediction of an LVEF improvement of at least 10 percentage points (Table 4).

In univariate logistic regression models, an increase in HRV5 of more than $23 \mathrm{~ms}$, an increase in the daily average cycle length of more than $112 \mathrm{~ms}$, and an increase in the daily step count of more than 1163 steps at day 45 were all significant predictors of $\geq 10 \%$ absolute LVEF improvement by three months. Other significant predictors of improvement were female sex, younger age, non-ischemic cardiomyopathy, and a lower baseline LVEF. When using the significant covariates in a multivariate regression, non-ischemic cardiomyopathy, lower baseline LVEF, and HRV5 increase were still significant predictors (Table 5). 
A

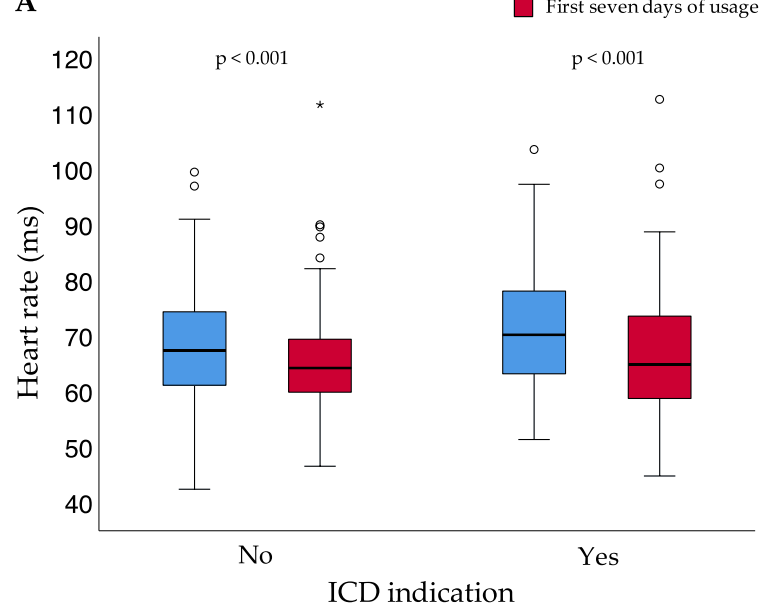

B

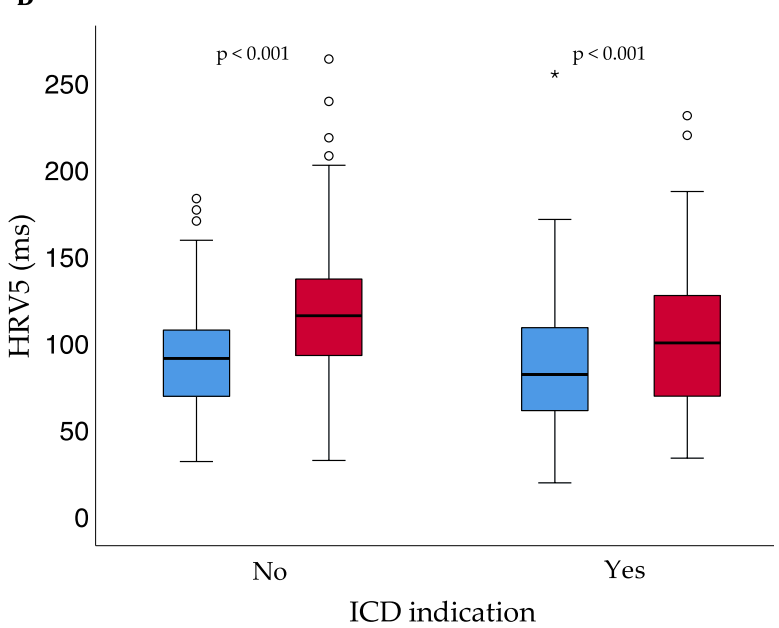

C

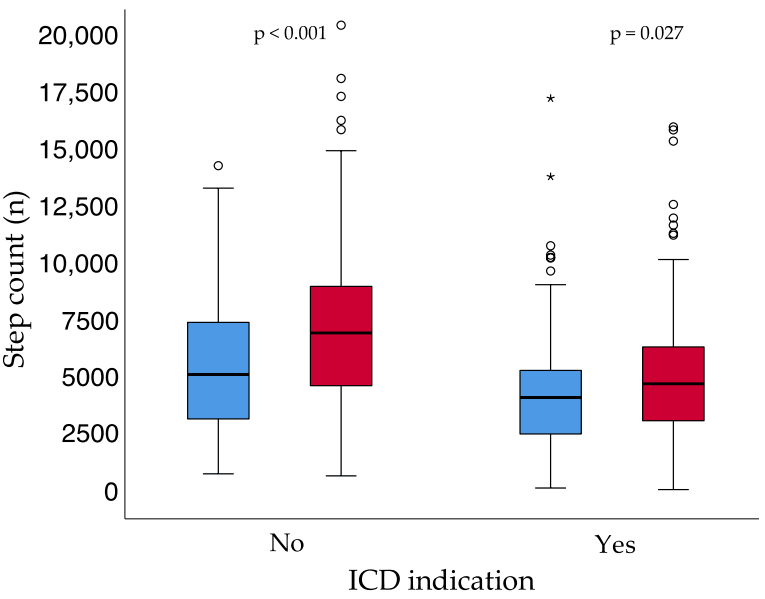

Figure 5. Heart rate (A), heart rate variability approximate (B), and step count (C) for the first and last seven days of usage for patients with and without ICD indication after the end of WCD prescription time; small circles represent outliers (data points outside the range of 3rd quartile $+1.5^{*}$ interquartile range or 1st quartile $-1.5^{*}$ interquartile range); asterisk represent extreme outliers (data points outside the range of 3 rd quartile $+3^{*}$ interquartile range or 1 st quartile $-3^{*}$ interquartile range); bpm = beats per minute; ICD = implantable cardioverter-defibrillator; HRV5 = heart rate variability approximate. 
Table 4. Area under the receiver operating curve (AUC) and optimal threshold for the change in daily average heart rate expressed as cycle length $(\triangle \mathrm{CL})$, the difference in HRV5 ( $\triangle \mathrm{HRV} 5)$, and the difference in daily step count ( $\Delta$ steps) for the prediction of an absolute LVEF improvement of $\geq 10 \%$; $\mathrm{AUC}=$ area under the curve; HRV5 = heart rate variability approximate; $\mathrm{CL}=$ cycle length .

\begin{tabular}{ccc}
\hline Parameter & AUC & Optimal Cut-Off \\
\hline$\Delta$ HRV5 & 0.678 & $23 \mathrm{~ms}$ \\
$\Delta$ CL & 0.566 & $112 \mathrm{~ms}$ \\
$\Delta$ steps & 0.625 & 1163 steps \\
\hline
\end{tabular}

Table 5. Univariate and multivariate logistic regression for an LVEF improvement of at least $10 \%$ between prescription and three-month follow-up with the delta of HRV5 and CL measured within the first 45 days of WCD wear time; $\mathrm{WCD}=$ wearable cardioverter-defibrillator; $\mathrm{LVEF}=$ left ventricular ejection fraction; $\mathrm{SD}=$ standard deviation; $\mathrm{CL}=\mathrm{cycle}$ length; ICM = ischemic cardiomyopathy; HRV5 = heart rate variability approximate. In 10 patients no exact LVEF at three months was available and thus no response could be classified. $p$-values given are for logistic regression models, see text.

\begin{tabular}{|c|c|c|c|c|c|}
\hline Parameters & $\begin{array}{c}\text { LVEF } \\
\text { Improvement }<10 \% \\
(n=143)\end{array}$ & 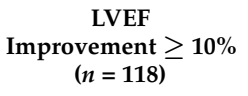 & $p$-Value (uni) & $\begin{array}{l}\text { Odds Ratio in } \\
\text { Multivariate Analysis } \\
(95 \%-C I)\end{array}$ & $p$-Value (Multi) \\
\hline Female Sex $(n, \%)$ & $39(27.3 \%)$ & $47(39.8 \%)$ & 0.032 & $1.02(0.51-2.05)$ & 0.95 \\
\hline Age (mean \pm SD) & $60.9 \pm 14.3$ & $52.6 \pm 15.5$ & $<0.001$ & $\begin{array}{l}0.98(0.96-1.01) \\
\text { per year }\end{array}$ & 0.130 \\
\hline $\operatorname{ICM}(n, \%)$ & $69(48.3 \%)$ & $22(18.6 \%)$ & $<0.001$ & $0.39(0.18-0.84)$ & 0.018 \\
\hline Baseline LVEF ( $\%$; mean \pm SD) & $27.0 \pm 8.4$ & $22.5 \pm 7.1$ & $<0.001$ & $\begin{array}{c}0.92(0.88-0.96) \\
\text { per percentage point }\end{array}$ & $<0.001$ \\
\hline$\Delta \mathrm{HRV} 5(\mathrm{~ms} ;$ mean $\pm \mathrm{SD})$ & $12.9 \pm 39.9$ & $38.8 \pm 42.2$ & $<0.001$ & $\begin{array}{c}2.13(1.05-4.32) \\
\text { for } \Delta H R V 5>23 \mathrm{~ms}\end{array}$ & 0.035 \\
\hline$\Delta \mathrm{CL}(\mathrm{ms} ;$ mean $\pm \mathrm{SD})$ & $28.1 \pm 119.0$ & $54.6 \pm 154.4$ & $<0.001$ & $\begin{array}{c}1.98(0.89-4.44) \\
\text { for } \Delta C L>112 \mathrm{~ms}\end{array}$ & 0.093 \\
\hline$\Delta$ steps $(n ;$ mean $\pm \mathrm{SD})$ & $1470 \pm 3322$ & $3287 \pm 4057$ & 0.002 & $\begin{array}{c}1.94(0.99-3.86) \\
\text { for } \Delta \text { steps }>1163\end{array}$ & 0.054 \\
\hline
\end{tabular}

\section{Discussion}

The present study evaluated for the first-time heart failure parameters recorded via the WCD in patients with newly diagnosed heart failure. The main findings are:

1. Patients with newly diagnosed HFrEF show a decrease in heart rate, as well as an increase in heart rate variability approximate and step count during the first three months of heart failure treatment.

2. A higher delta of heart rate or step count between the first and last seven days of usage correlates with a higher delta of the heart rate variability approximate.

3. A delta of heart rate variability approximately $>23 \mathrm{~ms}$ within the first 45 days of WCD wear time was an independent predictor of LVEF improvement.

This study is the first to analyze the parameters heart rate and step count, as provided and continuously monitored by the WCD additionally to SCD prevention. Patients with newly diagnosed HFrEF without meeting ICD implantation criteria were included in this analysis, representing a well-established indication for WCD prescription $[16,17,23]$. Patient characteristics in this study were comparable to previous studies regarding the use of the WCD [17,24-26]. Heart rate and heart rate variability are especially important parameters for heart failure therapy optimization and long-term management of heart failure [19]. Analyzed heart failure parameters were provided in short 5-min intervals, representing a real-time overview during day and night.

\subsection{Heart Rate}

Several population-based cohort studies have shown an association between a higher resting heart rate and cardiovascular mortality [27-30]. Moreover, a lower resting heart rate is associated with a lower mortality rate in patients suffering from HFrEF, especially in sinus rhythm [31]. In patients with ischemic cardiomyopathy, a higher resting heart rate is a known factor for a severe outcome [32,33] and is associated with the infarct size after myocardial infarction [34]. In patients with dilated idiopathic cardiomyopathy, 
a higher resting heart rate is associated with a lower LVEF [35] and is a predictor for arrhythmic events [36]. A resting heart rate $<70 \mathrm{bpm}$ is recommended in symptomatic patients with HFrEF, a severely reduced LVEF, and sinus rhythm [19]. Online monitoring using the WCD heart rate monitor may support reaching this aim during up-titration of heart failure medication [37].

In this study, patients showed a significant decrease in heart rate, most likely attributed to an early start of heart failure therapy. There is a further increase in heart rate during WCDwear time after recompensation and during further heart failure therapy optimization. Data showed a positive correlation between the delta of heart rate and HRV5. Nevertheless, there was no significant correlation between the delta of heart rate and step counts per day. Furthermore, there was no significant correlation between heart rate and LVEF.

\subsection{Heart Rate Variability}

Heart rate variability is a noninvasive method to assess the automatic nervous system function and the automatic activity in patients suffering from cardiovascular diseases [21]. A higher heart rate variability suggests a higher parasympathetic activity [21]. Reduced heart rate variability is a known predictor for mortality in patients with ischemic cardiomyopathy after myocardial infarction [21] or non-ischemic cardiomyopathy [38]. Furthermore, it is a predictor for hospitalization in HFrEF patients with cardiac resynchronization therapy [39].

In this study, we calculated an approximate for the heart rate variability using the standard deviation of the cycle lengths of the given five-minute heart rate data, based on the heart rate variability component SDANN.

We found a significant positive correlation between the delta of HRV5 and the delta of step counts per day between the first and last seven days of usage. A higher number of step counts per day suggests a higher amount of exercise per day. Results of this study are in line with previous studies, which have shown a correlation between exercise and heart rate variability [40-42]. There was a significant correlation between the delta of HRV5 between the first and last seven days of usage and the delta of LVEF, an important predictor for sudden cardiac death [4], when measured at prescription and three-month follow-up. This effect may be due to an early start of heart failure medication with an effective dosage and a continued heart failure therapy optimization during follow-up. Furthermore, a delta of HRV > $23 \mathrm{~ms}$ within the first 45 days of WCD wear time was shown as an independent predictor of LVEF improvement. Measurement of the heart rate variability using the WCD may be a helpful tool for early prediction of recovery and non-recovery and, therefore, as an early indicator of treatment response, important for HFrEF management.

\subsection{Step Count}

Step count monitoring is popular in the general population, using wearable devices such as smartphones, smartwatches, or wearable pedometers [43]. Just as described above for the resting heart rate, population-based cohort studies showed that a higher number of steps per day correlated with a lower mortality rate in a cohort of adults [44]. In the MADIT-CRT trial, a reduction in activity level was evaluated as a short-term predictor for adverse cardiovascular events in patients with heart failure and implanted cardiac resynchronization device [45].

The present study showed an increase in step count per day over time, which reflected an improvement in heart failure symptoms after initiation and up-titrating of heart failure medication. Moreover, a higher delta of step count per day between the first and last seven days of usage correlated with a higher delta of the LVEF, when measured at prescription and 3-month follow-up.

\subsection{Predictors of LVEF Improvement and Clinical Application}

In the present study, ischemic cardiomyopathy and a higher LVEF at baseline were shown to be independent predictors for an LVEF improvement of less than 10 points at 
the 3-month follow-up. In comparison, a delta of HRV5 $>23$ ms within the first 45 days of wear-time was shown to be an independent predictor for LVEF improvement $>10 \%$ between prescription and 3-month follow-up. An improvement in LVEF with more than 10 percentage points between the beginning of prescription and three-month follow-up was used as the cut-off for LVEF improvement. The cut-off is comparable to the used cut-off in other studies for identifying responders to heart failure therapy [46]. Furthermore, it has been shown to be an independent predictor for a better long-term outcome in patients with heart failure [47]. Whereas indication and baseline LVEF are known and non-changeable factors at prescription in patients with newly diagnosed heart failure, the heart rate variability is a dynamic parameter.

Via remote monitoring, it may be possible to closely monitor analyzed heart failure parameters in patients prescribed with a WCD. Analyzed parameters, especially heart rate variability, can be used for clinical decision-making during heart failure therapy. This process may improve heart failure management using the WCD.

Patients with a significant change in HRV5 until day 45 may be more likely to be LVEFimprovers at the 3-month follow-up. Furthermore, LVEF improvers without reaching a LVEF > 35\% at the 3-month follow-up may benefit especially from prolonged WCDprescription time. Further, prospective studies are needed to confirm this result. On the other hand, patients without an adequate change regarding heart failure parameters, especially the improvement in HRV5, can be selected early. Lack of HRV5 improvement at 45 days could trigger additional interventions, such as additional in-office visits and more aggressive optimization of medical treatment for HFrEF to increase the possibility of LVEF-improvement and avoid ICD-implantation. In contrast to other remote heart failure monitoring systems [48-50], no additional devices are needed to monitor heart failure parameters important for LVEF improvement in patients with HFrEF and prescribed WCD.

Management of heart failure therapy and, therefore, LVEF at the 3-month follow-up may be improved, and the number of patients without a need of an ICD device may increase due to the possibility of closer monitoring of additional heart failure parameters.

\subsection{Limitations}

This study represents a real-world collective with the known limitations of retrospective analyses. In order to aim for robust and complete datasets, only patients with a wear time of at least $20 \mathrm{~h}$ per day were included in this study, resulting in a selection bias. Furthermore, heart rate variability data were only provided in 5-min intervals. Thus, we derived HRV5 as an approximate metric of heart rate variability.

\section{Conclusions}

The WCD provides heart failure monitoring using additional parameters. Patients with newly diagnosed HFrEF showed significant changes in heart rate, step count per day, and heart rate variability during WCD prescription. Heart rate variability was an independent predictor for LVEF improvement and could serve as an early indicator of treatment response. Remote monitoring for heart failure parameters might be helpful for close monitoring and further HFrEF therapy optimization during WCD wearing.

Author Contributions: H.A.K.H. and S.H. contributed equally to this manuscript. H.A.K.H. designed the study, acquisitioned the data, performed the analysis, interpreted the data, and drafted the manuscript. S.H. performed the analysis and interpreted the data and drafted the manuscript. J.M.-L., C.Z., J.E. and J.B. revised the manuscript and provided substantial intellectual content. C.V. provided relevant intellectual contribution, revised the manuscript, and provided important supervision. D.D. designed the study, analyzed the data and drafted and revised the manuscript. All authors reviewed and edited the full manuscript. All authors have read and agreed to the published version of the manuscript.

Funding: This research received no external funding. 
Institutional Review Board Statement: The present study was conducted in compliance with the Declaration of Helsinki and approved by the Ethics Committee of Hannover Medical School, Germany.

Informed Consent Statement: All patients gave informed consent.

Data Availability Statement: The data of this study are available from the corresponding author, D.D., upon reasonable request.

Conflicts of Interest: D.D. received a modest lecture honorary, travel grants and/or a fellowship grant from Abbott, Astra Zeneca, Biotronik, Boehringer Ingelheim, Boston Scientific, Bristol Myers Squibb, Medtronic, Microport, Pfizer, Zoll. C.V. received honoraria for lectures, consulting and/or research funding from Abbott, Astra Zeneca, Bayer, Biotronik, Boehringer Ingelheim, Boston Scientific, CVRx, Medtronic, Pfizer, Roche. J.B. received honoraria for lectures and/or consulting from Novartis, BMS, Pfizer, Vifor, Bayer, Servier, Daichii Sankyo, CVRx, MSD, Boehringer Ingelheim, AstraZeneca, Abiomed, Abbott, Medtronic; and research support from Zoll, CVRx, Vifor, Abiomed. J.M. received a modest lecture honorary, travel grants and/or a fellowship grant from Medtronic and Boston Scientific. C.Z. received a modest lecture honorary, travel grants and/or a fellowship grant from Medtronic and Biotronik. S.H. received an educational grant from Boston Scientific.

\section{References}

1. Duncker, D.; Haghikia, A.; König, T.; Hohmann, S.; Gutleben, K.-J.; Westenfeld, R.; Oswald, H.; Klein, H.; Bauersachs, J.; Hilfiker-Kleiner, D.; et al. Risk for ventricular fibrillation in peripartum cardiomyopathy with severely reduced left ventricular function-value of the wearable cardioverter/defibrillator. Eur. J. Heart Fail. 2014, 16, 1331-1336. [CrossRef] [PubMed]

2. Duncker, D.; König, T.; Hohmann, S.; Bauersachs, J.; Veltmann, C. Ventricular arrhythmias in patients with newly diagnosed nonischemic cardiomyopathy: Insights from the PROLONG study. Clin. Cardiol. 2017, 40, 586-590. [CrossRef] [PubMed]

3. Olgin, J.E.; Pletcher, M.J.; Vittinghoff, E.; Wranicz, J.; Malik, R.; Morin, D.P.; Zweibel, S.; Buxton, A.E.; Elayi, C.S.; Chung, E.H.; et al. Wearable Cardioverter-Defibrillator after Myocardial Infarction. N. Engl. J. Med. 2018, 379, 1205-1215. [CrossRef] [PubMed]

4. Priori, S.G.; Blomström-Lundqvist, C.; Mazzanti, A.; Blom, N.; Borggrefe, M.; Camm, J.; Elliott, P.M.; Fitzsimons, D.; Hatala, R.; Hindricks, G.; et al. 2015 ESC Guidelines for the management of patients with ventricular arrhythmias and the prevention of sudden cardiac death. Eur. Heart J. 2015, 36, 2793-2867. [CrossRef] [PubMed]

5. Deneke, T.; Bosch, R.; Eckardt, L.; Nowak, B.; Schwab, J.O.; Sommer, P.; Veltmann, C.; Helms, T.M. Der tragbare Kardioverter/Defibrillator (WCD)—Indikationen und Einsatz. Der Kardiol. 2019, 13, 292-304. [CrossRef]

6. Al-Khatib, S.M.; Stevenson, W.G.; Ackerman, M.J.; Bryant, W.J.; Callans, D.J.; Curtis, A.B.; Deal, B.J.; Dickfeld, T.; Field, M.E.; Fonarow, G.C.; et al. 2017 AHA/ACC/HRS Guideline for Management of Patients With Ventricular Arrhythmias and the Prevention of Sudden Cardiac Death. Circulation 2018, 138, e91-e220.

7. Duncker, D.; Westenfeld, R.; Konrad, T.; Pfeffer, T.; Correia de Freitas, C.A.; Pfister, R.; Thomas, D.; Fürnkranz, A.; Andrié, R.P.; Napp, A.; et al. Risk for life-threatening arrhythmia in newly diagnosed peripartum cardiomyopathy with low ejection fraction: A German multi-centre analysis. Clin. Res. Cardiol. 2017, 106, 582-589. [CrossRef]

8. Epstein, A.E.; Abraham, W.T.; Bianco, N.R.; Kern, K.B.; Mirro, M.; Rao, S.V.; Rhee, E.K.; Solomon, S.D.; Szymkiewicz, S.J. Wearable Cardioverter-Defibrillator Use in Patients Perceived to Be at High Risk Early Post-Myocardial Infarction. J. Am. Coll. Cardiol. 2013, 62, 2000-2007. [CrossRef]

9. Zishiri, E.T.; Williams, S.; Cronin, E.M.; Blackstone, E.H.; Ellis, S.G.; Roselli, E.E.; Smedira, N.G.; Gillinov, A.M.; Glad, J.A.; Tchou, P.J.; et al. Early Risk of Mortality after Coronary Artery Revascularization in Patients with Left Ventricular Dysfunction and Potential Role of the Wearable Cardioverter Defibrillator. Circ. Arrhythmia Electrophysiol. 2013, 6, 117-128. [CrossRef]

10. Rao, M.; Goldenberg, I.; Moss, A.J.; Klein, H.; Huang, D.T.; Bianco, N.R.; Szymkiewicz, S.J.; Zareba, W.; Brenyo, A.; Buber, J.; et al. Wearable Defibrillator in Congenital Structural Heart Disease and Inherited Arrhythmias. Am. J. Cardiol. 2011, 108, 1632-1638. [CrossRef]

11. Opreanu, M.; Wan, C.; Singh, V.; Salehi, N.; Ahmad, J.; Szymkiewicz, S.J.; Thakur, R.K. Wearable cardioverter-defibrillator as a bridge to cardiac transplantation: A national database analysis. J. Hear. Lung Transplant. 2015, 34, 1305-1309. [CrossRef]

12. Salehi, N.; Nasiri, M.; Bianco, N.R.; Opreanu, M.; Singh, V.; Satija, V.; Jhand, A.S.; Karapetyan, L.; Safadi, A.R.; Surapaneni, P.; et al. The Wearable Cardioverter Defibrillator in Nonischemic Cardiomyopathy: A US National Database Analysis. Can. J. Cardiol. 2016, 32, 1247.e1-1247.e6. [CrossRef]

13. Wäßnig, N.K.; Günther, M.; Quick, S.; Pfluecke, C.; Rottstädt, F.; Szymkiewicz, S.J.; Ringquist, S.; Strasser, R.H.; Speiser, U. Experience With the Wearable Cardioverter-Defibrillator in Patients at High Risk for Sudden Cardiac Death. Circulation 2016, 134, 635-643. [CrossRef]

14. Erath, J.W.; Vamos, M.; Benz, A.P.; Hohnloser, S.H. Usefulness of the WCD in patients with suspected tachymyopathy. Clin. Res. Cardiol. 2018, 107, 70-75. [CrossRef]

15. Duncker, D.; Veltmann, C. The Wearable Cardioverter/Defibrillator-Toy or Tool? J. Atr. Fibrillation 2016, 8, 1367.

16. Duncker, D.; Veltmann, C. Role of the Wearable Defibrillator in Newly Diagnosed Heart Failure. Curr. Heart Fail. Rep. 2018, 15, 368-375. [CrossRef] [PubMed] 
17. Duncker, D.; König, T.; Hohmann, S.; Bauersachs, J.; Veltmann, C. Avoiding Untimely Implantable Cardioverter/Defibrillator Implantation by Intensified Heart Failure Therapy Optimization Supported by the Wearable Cardioverter/Defibrillator-The PROLONG Study. J. Am. Heart Assoc. 2017, 6, e004512. [CrossRef]

18. Mueller-Leisse, J.; Brunn, J.; Zormpas, C.; Hohmann, S.; Hillmann HA, K.; Eiringhaus, J.; Bauersachs, J.; Veltmann, C.; Duncker, D. Extended follow-up after wearable cardioverter-defibrillator period: The PROLONG-II study. ESC Hear. Fail. 2021. Online ahead of print. [CrossRef] [PubMed]

19. McDonagh, T.A.; Metra, M.; Adamo, M.; Gardner, R.S.; Baumbach, A.; Böhm, M.; Burri, H.; Butler, J.; Čelutkienė, J.; Chioncel, O.; et al. 2021 ESC Guidelines for the diagnosis and treatment of acute and chronic heart failure. Eur. Heart J. 2021, 42, 3599-3726. [CrossRef] [PubMed]

20. Lang, R.M.; Badano, L.P.; Mor-Avi, V.; Afilalo, J.; Armstrong, A.; Ernande, L.; Flachskampf, F.A.; Foster, E.; Goldstein, S.A.; Kuznetsova, T.; et al. Recommendations for Cardiac Chamber Quantification by Echocardiography in Adults: An Update from the American Society of Echocardiography and the European Association of Cardiovascular Imaging. J. Am. Soc. Echocardiogr. 2015, 28, 1-39.e14. [CrossRef]

21. Task Force of the European Society of Cardiology and the North American Society of Pacing Electrophysiology. Heart rate variability. Standards of measurement, physiological interpretation, and clinical use. Eur. Heart J. 1996, 17, 354-381. [CrossRef]

22. Robin, X.; Turck, N.; Hainard, A.; Tiberti, N.; Lisacek, F.; Sanchez, J.-C.; Müller, M. pROC: An open-source package for R and S+ to analyze and compare ROC curves. BMC Bioinform. 2011, 12, 77. [CrossRef] [PubMed]

23. Chung, M.K.; Szymkiewicz, S.J.; Shao, M.; Zishiri, E.; Niebauer, M.J.; Lindsay, B.D.; Tchou, P.J. Aggregate National Experience With the Wearable Cardioverter-Defibrillator. J. Am. Coll. Cardiol. 2010, 56, 194-203. [CrossRef] [PubMed]

24. Kutyifa, V.; Moss, A.J.; Klein, H.; Biton, Y.; McNitt, S.; MacKecknie, B.; Zareba, W.; Goldenberg, I. Use of the Wearable Cardioverter Defibrillator in High-Risk Cardiac Patients. Circulation 2015, 132, 1613-1619. [CrossRef]

25. Veltmann, C.; Winter, S.; Duncker, D.; Wäßnig, N.K.; Geller, J.C.; Erath, J.W.; Goeing, O.; Perings, C.; Ulbrich, M.; Roser, M.; et al. Protected risk stratification with the wearable cardioverter-defibrillator: Results from the WEARIT-II-EUROPE registry. Clin. Res. Cardiol. 2020, 110, 102-113. [CrossRef] [PubMed]

26. Zylla, M.M.; Hillmann HA, K.; Proctor, T.; Kieser, M.; Scholz, E.; Zitron, E.; Katus, H.A.; Thomas, D. Use of the wearable cardioverter-defibrillator (WCD) and WCD-based remote rhythm monitoring in a real-life patient cohort. Heart Vessels 2018, 33, 1390-1402. [CrossRef] [PubMed]

27. Kannel, W.B.; Kannel, C.; Paffenbarger, R.S.; Cupples, L.A. Heart rate and cardiovascular mortality: The Framingham study. Am. Heart J. 1987, 113, 1489-1494. [CrossRef]

28. Greenland, P.; Daviglus, M.L.; Dyer, A.R.; Liu, K.; Huang, C.F.; Goldberger, J.J.; Stamler, J. Resting heart rate is a risk factor for cardiovascular and noncardiovascular mortality: The Chicago Heart Association Detection Project in Industry. Am. J. Epidemiol. 1999, 149, 853-862. [CrossRef]

29. Kristal-Boneh, E.; Silber, H.; Harari, G.; Froom, P. The association of resting heart rate with cardiovascular, cancer and all-cause mortality. Eight year follow-up of 3527 male Israeli employees (the CORDIS Study). Eur. Heart J. 2000, 21, 116-124. [CrossRef]

30. Saxena, A.; Minton, D.; Lee, D.; Sui, X.; Fayad, R.; Lavie, C.J.; Blair, S.N. Protective role of resting heart rate on all-cause and cardiovascular disease mortality. Mayo Clin. Proc. 2013, 88, 1420-1426. [CrossRef]

31. Kotecha, D.; Flather, M.D.; Altman, D.G.; Holmes, J.; Rosano, G.; Wikstrand, J.; Packer, M.; Coats, A.J.S.; Manzano, L.; Böhm, M.; et al. Heart Rate and Rhythm and the Benefit of Beta-Blockers in Patients with Heart Failure. J. Am. Coll. Cardiol. 2017, 69, 2885-2896. [CrossRef] [PubMed]

32. Hjalmarson, A. Significance of reduction in heart rate in cardiovascular disease. Clin. Cardiol. 1998, 21, II3-7. [PubMed]

33. Hjalmarson, Å.; Gilpin, E.A.; Kjekshus, J.; Schieman, G.; Nicod, P.; Henning, H.; Ross, J. Influence of heart rate on mortality after acute myocardial infarction. Am. J. Cardiol. 1990, 65, 547-553. [CrossRef]

34. Stangeland, L.; Grong, K.; Vik-Mo, H.; Andersen, K.S.; Lekven, J. Is reduced cardiac performance the only mechanism for myocardial infarct size reduction during beta adrenergic blockade? Cardiovasc. Res. 1986, 20, 322-330. [CrossRef] [PubMed]

35. Clements, I.P.; Miller, W.L.; Olson, L.J. Resting heart rate and cardiac function in dilated cardiomyopathy. Int. J. Cardiol. 1999, 72, 27-37. [CrossRef]

36. Calé, R.; Mendes, M.; Brito, J.; Sousa, P.; Carmo, P.; Almeida, S.; Gomes, R.; Ferreira, A.; Santos, K.R.; Cavaco, D.; et al. Resting heart rate is a powerful predictor of arrhythmic events in patients with dilated cardiomyopathy and implantable cardioverter-defibrillator. Rev. Port. Cardiol. 2011, 30, 199-212.

37. Optimizing Beta Blocker Dosage in Women While Using the Wearable Cardioverter Defibrillator (OPT-BB WOMEN). Available online: https: / clinicaltrials.gov/ct2/show / NCT04504188 (accessed on 28 October 2021).

38. Rashba, E.J.; Estes NA, M.; Wang, P.; Schaechter, A.; Howard, A.; Zareba, W.; Couderc, J.-P.; Perkiomaki, J.; Levine, J.; Kadish, A. Preserved heart rate variability identifies low-risk patients with nonischemic dilated cardiomyopathy: Results from the DEFINITE trial. Heart Rhythm 2006, 3, 281-286. [CrossRef]

39. Swearingen, A.; Schafer, J.; De Lurgio, D.; Stone, J. SDANN as a Predictor of Heart Failure Hospitalizations in Cardiac Resynchronization Therapy Patients. J. Card. Fail. 2006, 12, S112-S113. [CrossRef]

40. Soares-Miranda, L.; Sattelmair, J.; Chaves, P.; Duncan, G.E.; Siscovick, D.S.; Stein, P.K.; Mozaffarian, D. Physical Activity and Heart Rate Variability in Older Adults. Circulation 2014, 129, 2100-2110. [CrossRef] 
41. Masroor, S.; Bhati, P.; Verma, S.; Khan, M.; Hussain, M.E. Heart Rate Variability following Combined Aerobic and Resistance Training in Sedentary Hypertensive Women: A Randomised Control Trial. Indian Heart J. 2018, 70, S28-S35. [CrossRef]

42. Sandercock GR, H.; Bromley, P.D.; Brodie, D.A. Effects of Exercise on Heart Rate Variability: Inferences from Meta-Analysis. Med. Sci. Sport. Exerc. 2005, 37, 433-439. [CrossRef] [PubMed]

43. Duncker, D.; Ding, W.Y.; Etheridge, S.; Noseworthy, P.A.; Veltmann, C.; Yao, X.; Bunch, T.J.; Gupta, D. Smart Wearables for Cardiac Monitoring-Real-World Use beyond Atrial Fibrillation. Sensors 2021, 21, 2539. [CrossRef] [PubMed]

44. Saint-Maurice, P.F.; Troiano, R.P.; Bassett, D.R.; Graubard, B.I.; Carlson, S.A.; Shiroma, E.J.; Fulton, J.E.; Matthews, C.E. Association of Daily Step Count and Step Intensity with Mortality among US Adults. JAMA—J. Am. Med. Assoc. 2020, 323, 1151-1160. [CrossRef] [PubMed]

45. Jamé, S.; Kutyifa, V.; Polonsky, B.; McNitt, S.; Al-Ahmad, A.; Moss, A.J.; Zareba, W.; Wang, P.J. Predictive value of device-derived activity level for short-term outcomes in MADIT-CRT. Heart Rhythm 2017, 14, 1081-1086. [CrossRef]

46. Jin, H.; Gu, M.; Hua, W.; Fan, X.-H.; Niu, H.-X.; Ding, L.-G.; Wang, J.; Xue, C.; Zhang, S. Predictors of super-response to cardiac resynchronization therapy: The significance of heart failure medication, pre-implant left ventricular geometry and high percentage of biventricular pacing. J. Geriatr. Cardiol. 2017, 14, 737-742.

47. Joshi, K.; Alam, I.; Ruden, E.; Gradus-Pizlo, I.; Mahenthiran, J.; Kamalesh, M.; Feigenbaum, H.; Sawada, S. Effect of improvement in left ventricular ejection fraction on long-term survival in revascularized patients with ischaemic left ventricular systolic dysfunction. Eur. J. Echocardiogr. 2011, 12, 454-460. [CrossRef]

48. Koehler, F.; Winkler, S.; Schieber, M.; Sechtem, U.; Stangl, K.; Böhm, M.; Boll, H.; Kim, S.S.; Koehler, K.; Lücke, S.; et al. Telemedical Interventional Monitoring in Heart Failure (TIM-HF), a randomized, controlled intervention trial investigating the impact of telemedicine on mortality in ambulatory patients with heart failure: Study design. Eur. J. Heart Fail. 2010, 12, 1354-1362. [CrossRef]

49. Koehler, J.; Stengel, A.; Hofmann, T.; Wegscheider, K.; Koehler, K.; Sehner, S.; Rose, M.; Deckwart, O.; Anker, S.D.; Koehler, F.; et al. Telemonitoring in patients with chronic heart failure and moderate depressed symptoms: Results of the Telemedical Interventional Monitoring in Heart Failure (TIM-HF) study. Eur. J. Heart Fail. 2021, 23, 186-194. [CrossRef]

50. Koehler, F.; Koehler, K.; Deckwart, O.; Prescher, S.; Wegscheider, K.; Winkler, S.; Vettorazzi, E.; Polze, A.; Stangl, K.; Hartmann, O.; et al. Telemedical Interventional Management in Heart Failure II (TIM-HF2), a randomised, controlled trial investigating the impact of telemedicine on unplanned cardiovascular hospitalisations and mortality in heart failure patients: Study design and description. Eur. J. Heart Fail. 2018, 20, 1485-1493. [CrossRef] 